\title{
Frequency Upconversion in Rare Earth lons
}

\author{
Vineet Kumar Rai \\ Laser and Spectroscopy Laboratory, Department of Applied Physics \\ Indian School of Mines, Dhanbad, Jharkhand, \\ India
}

\section{Introduction}

A large number of solid host materials have been considered to study the consequence of host materials on the lasing properties of the active ions since the development of the solid state lasers. With increasing interest in the photonic devices the appeal for employing photonic glasses has grown much interest because they may be chemically and mechanically stable hence being ideal for substituting the crystalline systems in many conditions. Rare earth doped solid materials are of great importance due to their wide range of applications in lasers, temperature sensors, optical amplifiers, etc. among other devices [Savage, 1987; Digonnet, 1993; Jackson, 2003; Rai, 2007]. Study of the spectroscopic properties of rare earth doped systems is very important from several points of view. The effect of environment on the energy levels, variations in their emission and absorption characteristics, upconversions observed in near infrared (NIR), visible pumping etc. can easily be studied from these. The longer lifetime of the energy levels is one of the prime requirements for lasing. Lasing in these rare earth ions occur due to the transition between the spin-orbit splitted components of the same state or between the states arising from the unfilled (4f) electronic configuration, which are usually forbidden as per electric dipole selection rules. The electric dipole transitions between states of the $4 \mathrm{f}$ configuration for free ions are strictly forbidden by the parity rule. The transitions can take only due to the mixing of states of opposite parity in the wave functions. The optical properties of rare earth ions doped solid host materials depend on the chemical composition of the host materials [Reisfield, 1973; Babu et al., 2000; Dumbaugh, 1992; Rai, 2006; Dieke et al., 1968; Ebendroff, 1996]. Rare earth ions are found to be very much sensitive to small changes in chemical surroundings. On the other hand network modifiers affect the local environment around the fluorescent ions and thereby its optical properties. Therefore, it becomes essential to get the information about the symmetry and bonding of the probe ion and how they change their optical properties with chemical composition of the solid host materials and also from site to site variations. In the solid host materials with higher phonon frequencies, it is not easy to get efficient infrared and visible emission even in the $\mathrm{Er}^{3+}, \mathrm{Nd}^{3+}, \mathrm{Ho}^{3+}, \mathrm{Tm}^{3+}$, etc. The effect of host materials on the optical properties of rare earth ions introduced as doping along with compositional changes of modifiers have been studied by different workers [Babu et al., 2000; Rai et al., 2006; Nageno et al., 1994; Tripathi et al., 2006; Rai, 2010; Rai et al., 2008; Sai Sudha et al., 1996; Lin et al., 2002; Hussain et al., 2000; Nachimuthu et al., 1997; Tripathi et al., 2006]. They concluded that 
due to their improved radiative transition probabilities, these glasses are promising materials for different technological applications.

For getting the high quantum efficiency, concentration of the rare earth ions should be high, but it may cause certain problems like concentration quenching due to the interaction between the excited and its unexcited neighbours. Therefore, in order to make the devices with high optical characteristics, the concentration of the rare earth ions has to be kept low so that the luminescence quenching is minimized. Specifically, the systems of main interest are those having low cut-off phonon frequencies, high refractive index etc. because in such systems the quantum efficiency for the rare earth ions introduced as doping is improved significantly [Yamane et al., 2000]. It is also possible to prevent the quenching effect by modifying the environment felt by the luminescent ions [Rai, 2010; Snoeks et al., 1995; Kumar et al., 2005]. Therefore, the glasses containing metallic nanoparticles doped with low concentration of rare earth ions are of particular interest because the large local field acting around the rare earth ions positioned near the nanoparticles may increase the luminescence efficiency when the frequency of the excitation beam and or / the luminescence frequency are near resonance with the surface plasmon frequency of the nanoparticles [Kumar et al., 2005]. There is a large demand in generation of visible light sources for different photonics applications. One effective way for generating visible light is the frequency upconversion in which the absorption of two or more photons is followed by the emission of high energy photon. Rare earth ions are the appropriate candidates for the frequency upconversion (UC) processes owing to their large number of energy levels, narrow emission spectral lines, long lifetime of excited states and they can be easily populated by the near-infrared radiation.

The study of frequency upconversion luminescence in lanthanides doped solid materials is mainly due to their potential applications in different areas such as color display, two photon imaging in confocal microscopy, high density optical data storage, upconvertors, under sea communications, IR lasers, indicators, temperature sensors, biomedical diagnostics etc. The main interest in recent years is concentrated in the identification of new upconversion mechanisms and their characterization in rare earth doped materials. Generally, the frequency upconversion may arise by any of the following mechanisms (a) A multiphoton absorption (b) Energy transfer interaction (c) Excited state absorption (d) Avalanche energy transfer.

Excited state absorption (ESA) involves single ion, which depends on multistep absorption in individual ion, while the frequency upconversion through energy transfer between groups of rare earth ions can be very efficient and therefore can be used in making upconversion lasers [Yamane et al.,2000; Kassab et al., 2007; Silva et al., 2007]. The upconversion phenomenon are motivated not only by attempts to enrich the fundamental knowledge for understanding the mechanism of interaction between the rare earth ions doped into a variety of host materials but also the search for new light sources emitting in the visible region. Keeping in mind the attention has been paid to solid host materials doped with rare earth ions that show strong and broad absorption bands matching with the emission wavelength of commercial diodes [Yamane et al., 2000; Kaminskii, 1990; Kaplyanskii, 1987; Kenyon, 2002; Lezama et al., 1985].

Solid host materials based on heavy metal oxides are of particular interest for different photonics applications due to their low cut -off phonon energy and large refractive index 
[Rai et al., 2008; Yamane et al., 2000]. In hosts with low cut-off phonon energies, the luminescence intensity of rare earth ions is enhanced by several times [Digonnet 1993; Rai et al., 2006; Kenyon, 2002]. This enhancement is neither due to any external field nor a Maxwell field, which was explained in detail very early on by Lorentz, but due to the local field which depends on the presence of all the other atoms in the dielectric [Born et al., 1999]. Inorganic glasses have been used as optical materials for a long time due to their isotropy, hence to make the large size and high optical homogeneity more easily, and high transparency over a wide spectral range from ultraviolet to infrared, as well as linear functional properties, high mechanical strength, high chemical resistance and simple fabrication procedures for obtaining good optical quality samples. The host materials of main interest are those for which the quantum efficiency of rare earth ions luminescence is enhanced, allowing the development of more efficient lasers, upconvertors, optical amplifiers, etc. [Yamane et al., 2000; El-Mallawany, 2001]. The present chapter deals with the frequency upconversion in some of the lanthanides, specially $\mathrm{Pr}^{3+}$ and $\mathrm{Nd}^{3+}$ doped solid host materials and different excitation processes, mainly, excited state absorption (ESA) and the energy transfer (ET) processes responsible for the luminescence in the rare earth ions.

\section{Frequency upconversion in triply ionized lanthanides doped in solid host materials}

The frequency upconversion 'conversion of low energy photon into higher energy photon' emission is receiving significant attention due to a variety of photonic applications. Glassy materials doped with rare earth ions are capable of high peak power generation due to their high saturation frequencies, broad emission bandwidths etc. The oxide glasses have compatibility with waveguide fabrication process and their optical damage threshold is quite high. They have high chemical and thermal stability and are thus suitable materials for technological applications. However, the high phonon energy corresponding to the stretching vibrations of the oxide glass network modifiers creates difficulty in generation of upconversions. The frequency upconversion in rare earth ions doped fluoride, ZBLAN and ZBS based glasses has also been observed, but due to its hygroscopic nature their applications are limited [Oliveria et al., 1998; Parker, 1989]. The frequency upconversion in lanthanides doped solid host materials has been studied by several workers [Pacheco et al., 1988; Pelle et al., 1993; Mujaji et al., 1993; Victor et al., 2002; Rai et al., 2006; Rai et al., 2007; Rai et al., 2008; Rai et al., 2008; Rai, 2009; Tripathi et al., 2007; Mohanty et al., 2011; Balda et al., 1999; Ganem et al., 1992; Smart et al., 1991; Luis et al., 1994].

\subsection{Frequency upconversion in $\mathrm{Pr}^{3+}$ doped glasses}

Triply ionized praseodymium doped glasses and crystals are one of the most extensively studied systems because of their wide applications in many optical devices. $\mathrm{The}^{\mathrm{Pr}^{3+}}$ contains several metastable states that provides the possibility of simultaneous emissions in the blue, green, orange, red and infrared (IR) regions [Kaminskii, 1990]. Upconversion (UC) emission has been observed in $\mathrm{Pr}^{3+}$ doped different glasses as well as crystal lattices [Rai et al., 2006; Rai et al., 2007; Rai et al., 2008; Rai et al., 2008; Rai, 2009; Balda et al., 1999; Ganem et al., 1992; Smart et al., 1991; Luis et al., 1994]. Among the heavy metal oxide (HMO) glasses the ones based on tellurium oxide $\left(\mathrm{TeO}_{2}\right)$ are important candidates to be used in practical devices because they present high mechanical strength, high chemical durability, high optical damage 
threshold, and small absorption coefficient over the visible and near infrared regions of the electromagnetic spectrum. Furthermore, in general these glasses are nonhygroscopic and can be fibered. Frequency upconversion in $\mathrm{Pr}^{3+}$ doped tellurite based glasses has been studied by different workers [Rai et al., 2006; Rai et al., 2007; Rai et al., 2008; Rai et al., 2008; Rai, 2009; Balda et al., 1999]. For excitation of the samples the NIR radiation from a Ti-sapphire laser pumped by second harmonic of $\mathrm{Nd}: \mathrm{YVO}_{4}$ (yttrium vanadate) (CW) laser [Rai et al., 2006; Rai et al., 2007] as well as a Nd:YAG (yttrium aluminum garnet) laser pumped dye laser (8 ns pulses, tunable from 570 to $600 \mathrm{~nm}$ ) was used [Rai et al., 2007; Rai et al., 2008; Rai, 2009; Balda et al., 1999] as an excitation source. The excitation beam was focused onto the sample with a lens and the fluorescence was collected in a direction perpendicular to the incident beam; the signal was analyzed by a monochromator attached with a photomultiplier tube. All the measurements were made at room temperature.

\section{2 (a) Excited state absorption (ESA)}

The upconversion emission in triply ionized praseodymium doped $\mathrm{TeO}_{2}-\mathrm{Li}_{2} \mathrm{O}$ glass upon CW excitation from a Ti-sapphire laser has been reported [Rai et al., 2007]. The absorption spectrum of $0.5 \mathrm{~mol} \%$ of $\operatorname{Pr}^{3+}$ doped tellurite glass shows four absorption bands in the 400 $800 \mathrm{~nm}$ region (Fig. 1). These absorptions bands are mainly due to the transitions from the ground $\left({ }^{3} \mathrm{H}_{4}\right)$ state to the ${ }^{3} \mathrm{P}_{2},{ }^{3} \mathrm{P}_{1},{ }^{3} \mathrm{P}_{0}$ and ${ }^{1} \mathrm{D}_{2}$ excited states. Upconversion emission in the $\mathrm{Pr}^{3+}$ doped $\mathrm{TeO}_{2}-\mathrm{Li}_{2} \mathrm{O}$ glasses upon excitation at $\sim 816 \mathrm{~nm}$ from a Ti-sapphire laser has been observed in the blue, orange and red regions corresponding to the ${ }^{3} \mathrm{P}_{2} \rightarrow{ }^{3} \mathrm{H}_{4},{ }^{3} \mathrm{P}_{0} \rightarrow{ }^{3} \mathrm{H}_{4}$, ${ }^{3} \mathrm{P}_{1} \rightarrow{ }^{3} \mathrm{H}_{5},{ }^{3} \mathrm{P}_{0} \rightarrow{ }^{3} \mathrm{H}_{5},{ }^{1} \mathrm{D}_{2} \rightarrow{ }^{3} \mathrm{H}_{4}$ and ${ }^{3} \mathrm{P}_{0} \rightarrow 3 \mathrm{~F}_{2}$ transitions. Thus upconversion at several wavelengths can be obtained by pumping with single NIR wavelength. It is well known that the upconversion luminescence intensity $\left(\mathrm{I}_{0}\right)$ is proportional to the $\mathrm{n}^{\text {th }}$ power of the pump intensity $\left(I_{i}\right)$, where ' $n$ ' is the number of pump photons required to populate the emitting level. To ascertain the number of photons involved in the upconversion process the intensity of the emitted band was measured as a function of NIR radiation power. The slope of the graph $\log \mathrm{I}_{0}$ versus $\log \mathrm{I}_{\mathrm{i}}$ gives a value $\sim 1.93$ for ${ }^{3} \mathrm{P}_{0} \rightarrow{ }^{3} \mathrm{~F}_{2}$ transition, indicating that two photons are involved in the upconversion process.

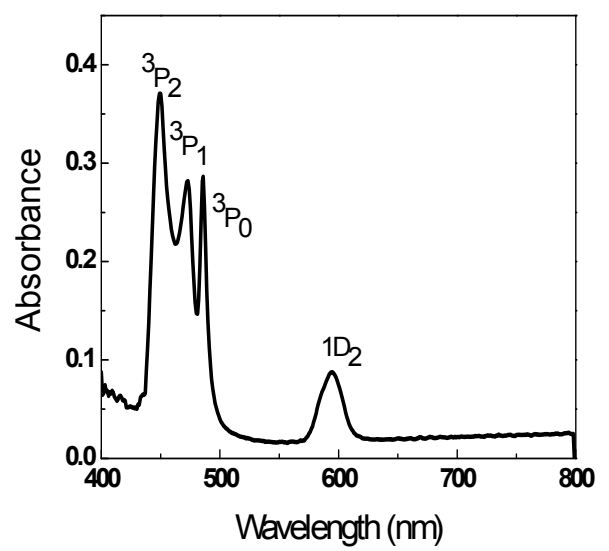

Fig. 1. Absorption spectrum of $0.5 \mathrm{~mol} \% \mathrm{Pr}^{3+}$ doped $\mathrm{TeO}_{2}-\mathrm{Li}_{2} \mathrm{O}$ glass. Reprinted with permission from ref. (Rai, 2009), Copyright 2009, Springer. 
In the present case, ${ }^{3} \mathrm{P}_{\mathrm{J}}$ as well as ${ }^{1} \mathrm{D}_{2}$ levels are populated as a result of two photon absorption resulting upconversion transition to various lower lying levels. The upconversion luminescence may arise by one of the following mechanisms: (a) Sequential absorption of two photons, (b) excited state absorption (ESA), (c) photon avalanche and (d) energy transfer (ET) processes. In this case the upconversion emission is observed even at lower pump power of the laser, the upconversion emission by sequential absorption of two photons is ruled out. Now, if we consider the energy level diagram of $\operatorname{Pr}^{3+}$ (Fig. 2), ${ }^{1} \mathrm{G}_{4}$ level of it lies at $\sim 9850 \mathrm{~cm}^{-1}$. The energy corresponding to NIR radiation is $\sim 12252 \mathrm{~cm}^{-1}$. The ${ }^{1} \mathrm{G}_{4}$ level is therefore excited through phonon-assisted excitation. The phonon energy of $\mathrm{TeO}_{2}$ lattice is $\sim 650 \mathrm{~cm}^{-1}$ which requires four phonons to be involved in the process. If upconversion emission is due to energy transfer process between two $\mathrm{Pr}^{3+}$ ions, the excited $\mathrm{Pr}^{3+}$ ions in ${ }^{1} \mathrm{G}_{4}$ state transfer its excitation energy to the next neighboring $\mathrm{Pr}^{3+}$ ion in this excited state. During this process one ion is excited to the upper level and other one return to the ground state. But the emission is observed from the levels lying at energy $\sim 22000 \mathrm{~cm}^{-1}$ also, therefore ET is not responsible at least for all upconversion emissions. May be that a part of intensity for the transitions from the levels lying at energy $<19700 \mathrm{~cm}^{-1}$ is contributed to this channel. But the upconversion emission bands do not show any significant concentration dependence. This also supports ET a less probable channel for upconversion emission. Since the dependence of the upconversion emission intensity versus pump power does not show any inflection, which confirms that the avalanche energy transfer is also not a reasonable process for the upconversion. Therefore the dominant mechanism may be most probably ESA. In this mechanism the excited $\mathrm{Pr}^{3+}$ ion in ${ }^{1} \mathrm{G}_{4}$ level reabsorbs another incident photon of the same energy and is promoted to ${ }^{3} \mathrm{P}_{\mathrm{J}}$ level. The excited ions from this state relax to different lower-lying excited states and give fluorescence corresponding to the ${ }^{3} \mathrm{P}_{2} \rightarrow{ }^{3} \mathrm{H}_{4}$, ${ }^{3} \mathrm{P}_{0} \rightarrow{ }^{3} \mathrm{H}_{4},{ }^{3} \mathrm{P}_{1} \rightarrow{ }^{3} \mathrm{H}_{5},{ }^{3} \mathrm{P}_{0} \rightarrow{ }^{3} \mathrm{H}_{5},{ }^{1} \mathrm{D}_{2} \rightarrow{ }^{3} \mathrm{H}_{4}\left({ }^{3} \mathrm{P}_{0} \rightarrow{ }^{3} \mathrm{H}_{6}\right)$ and ${ }^{3} \mathrm{P}_{0} \rightarrow{ }^{3} \mathrm{~F}_{2}$ transitions. Normally, upconversion emission is not observed from ${ }^{3} \mathrm{P}_{2}$ level; however in this case a weak upconversion emission from this state has also been detected. This may be due to exact energy matching at the second step. The upconversion emission was measured at different temperatures of the glass. It has been found that the upconversion emission decreases with increasing the temperature, which reveals that the upconversion is not due to any thermally

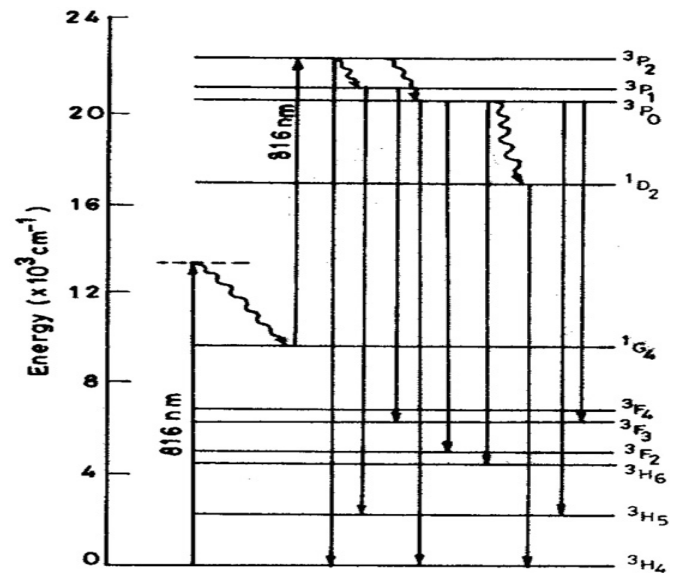

Fig. 2. Energy level diagram of $\operatorname{Pr}^{3+}$ (Rai et al., 2007) 
activated process. The upconversion efficiency for the ${ }^{3} \mathrm{P}_{0} \rightarrow 3 \mathrm{~F}_{2}$ transition at $0.5 \mathrm{~mol} \%$ concentration of $\mathrm{Pr}^{3+}$ doped in tellurite glass at room temperature $\left(\sim 30{ }^{0} \mathrm{C}\right)$ is found to be $\sim 1.7 \%$.

A broadband upconversion emission in $\mathrm{Pr}^{3+}$ doped aluminum, barium, calcium fluoride glass has been observed at different wavelengths throughout the visible region upon non resonant excitation $(\sim 810 \mathrm{~nm})$ corresponding to the ${ }^{3} \mathrm{H}_{4} \rightarrow{ }^{1} \mathrm{G}_{4}$ transition from a Ti-sapphire laser [Rai et al., 2006]. Upconversion emissions are observed for nearly all bands for which one photon fluorescence is seen. The peaks observed in orange-red region due to the ${ }^{1} \mathrm{D}_{2} \rightarrow{ }^{3} \mathrm{H}_{4}$ and ${ }^{3} \mathrm{P}_{0} \rightarrow{ }^{3} \mathrm{H}_{6}$ transitions are also observed in the fluorescence spectrum. One sharp upconversion peak observed near $641 \mathrm{~nm}$ is due to the ${ }^{3} \mathrm{P}_{\mathrm{o}} \rightarrow 3 \mathrm{~F}_{2}$ transition. Weak upconversion is also observed at $\sim 676$ and $\sim 731 \mathrm{~nm}$ and they are due to the ${ }^{3} \mathrm{P}_{1} \rightarrow{ }^{3} \mathrm{~F}_{3}$ and ${ }^{3} \mathrm{P}_{\mathrm{o}} \rightarrow 3 \mathrm{~F}_{4}$ transitions. Thus, using NIR radiation, one can get upconversion emissions throughout the visible region. The $\mathrm{Pr}^{3+}$ ions on absorption of $\sim 12,300 \mathrm{~cm}^{-1}$ radiation are promoted to the ${ }^{1} \mathrm{G}_{4}$ level through phonon assisted excitation. The upconversion emission from the ${ }^{3} \mathrm{P}_{\mathrm{J}}$ levels is observed, it is possible only when excited $\mathrm{Pr}^{3+}$ ion in the ${ }^{1} \mathrm{G}_{4}$ level reabsorb the second incident photon of the energy $\sim 12,300 \mathrm{~cm}^{-1}$ (i.e. the ESA process). Energy transfer (ET) amongst the excited ions will not be sufficient to populate the ${ }^{3} \mathrm{P}_{\mathrm{J}}$ levels. Therefore, the upconversion emissions observed in blue region are due to the excited state absorption (ESA). The ${ }^{3} \mathrm{P}_{\mathrm{J}}$ levels also give upconversion emissions in the orange and red regions. The ${ }^{1} \mathrm{D}_{2}$ level is populated by the relaxation from ${ }^{3} \mathrm{P}_{\mathrm{J}}$ levels. The other possibility of population to the ${ }^{1} \mathrm{D}_{2}$ level is via energy transfer (ET) among the $\mathrm{Pr}^{3+}$ ions, i.e.

$$
{ }^{1} \mathrm{G}_{4}+{ }^{1} \mathrm{G}_{4} \rightarrow{ }^{1} \mathrm{D}_{2}+{ }^{3} \mathrm{H}_{4}+\Delta \mathrm{E} \text { (phonon energy) }
$$

For this, the intensity of upconversion emission band corresponding to the ${ }^{1} \mathrm{D}_{2} \rightarrow{ }^{3} \mathrm{H}_{4}$ transition should be large enough and show a quadratic behavior with the concentration of rare earth ions, whereas the upconversion emission corresponding to the ${ }^{1} \mathrm{D}_{2} \rightarrow{ }^{3} \mathrm{H}_{4}$ transition appears weak. Therefore, the most probable process of the ${ }^{1} \mathrm{D}_{2}$ level population is via relaxation from ${ }^{3} \mathrm{P}_{\mathrm{J}}$ levels. The mechanism involved in the upconversion emissions observed in the visible region is due to excited state absorption (ESA).

\section{3 (b) Energy transfer (ET)}

Upconversion luminescence in triply ionized praseodymium-doped $\mathrm{TeO}_{2}-\mathrm{Li}_{2} \mathrm{O}$ glass using direct excitation into the ${ }^{1} \mathrm{D}_{2}$ level from a Nd:YAG (yttrium aluminum Garnet) laser pumped dye laser ( $\sim 8 \mathrm{~ns}$ pulses, tunable from 570 to $600 \mathrm{~nm}$; peak power: $\sim 20 \mathrm{~kW}$, linewidth: $\sim 0.5$ $\mathrm{cm}^{-1}$ ) has been reported [Rai, 2009]. The method for preparation of the doped glasses is reported elsewhere in detail [Rai et al., 2007]. The absorption spectrum of a $0.5 \mathrm{~mol} \%$ praseodymium doped glass sample in the 400-800nm is shown in Fig. 1. The band positions observed in the absorption spectrum are in good agreement with the values reported for the other glasses. The variations in their bandwidths and relative intensities are only due to the site-to-site variations of the crystal field strengths. The spectra observed for the other samples are similar, except for the band intensities and their line widths, which are concentration dependent. A simplified energy level scheme of the $\operatorname{Pr}^{3+}$ electronic levels is shown in Fig. 3. An intense luminescence at $\sim 480 \mathrm{~nm}$ and at $\sim 680 \mathrm{~nm}$ respectively corresponding to the ${ }^{3} \mathrm{P}_{0} \rightarrow{ }^{3} \mathrm{H}_{4}$ and ${ }^{1} \mathrm{D}_{2} \rightarrow{ }^{3} \mathrm{H}_{5}$ transitions was seen under the excitation at $\sim 590 \mathrm{~nm}$ (Fig. 4). Similar features were observed for all the doped samples with their 
relative intensities. The upconversion intensity shows a quadratic dependence with the laser intensity as well as with the concentration of the $\mathrm{Pr}^{3+}$ ions. Thus, two incident laser photons and two triply ionized praseodymium ions are responsible for this upconversion emission to occur, while for the emission at $\sim 680 \mathrm{~nm}$ ascribed to the ${ }^{1} \mathrm{D}_{2} \rightarrow{ }^{3} \mathrm{H}_{5}$ transition a linear dependence on the laser intensity as well as on the concentration of the rare-earth ions with the fluorescence intensity was observed. This confirms that the energy transfer is affecting the upconversion luminescence.

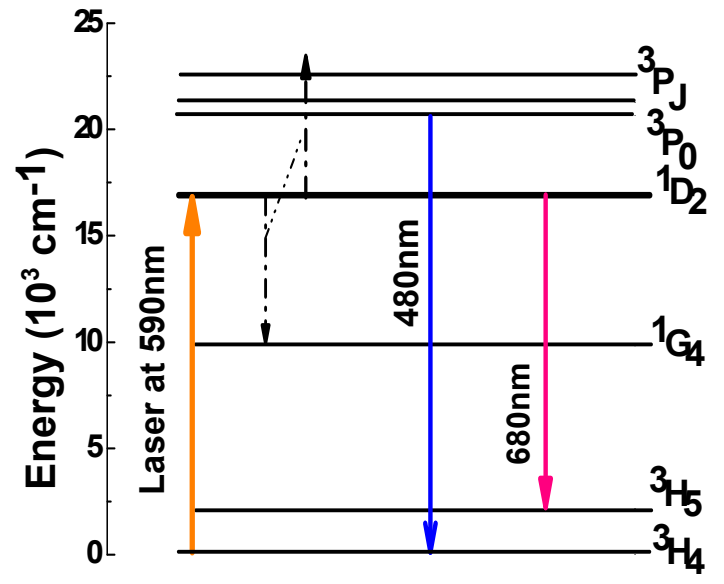

Fig. 3. Energy level diagram of $\operatorname{Pr}^{3+}$. Reprinted with permission from ref. (Rai, 2009), Copyright 2009, Springer.

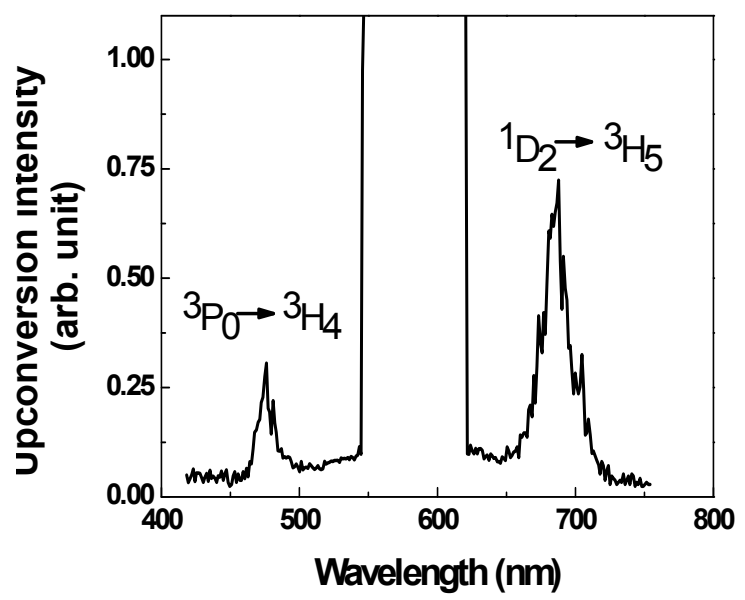

Fig. 4. Upconversion spectrum of $0.5 \mathrm{~mol} \% \mathrm{Pr}^{3+}$ doped $\mathrm{TeO}_{2}-\mathrm{Li}_{2} \mathrm{O}$ glass. Reprinted with permission from ref. (Rai, 2009), Copyright 2009, Springer.

In fact, a pair of neighboring $\operatorname{Pr}^{3+}$ ions in the ground state is excited by the two incident laser photons (at $\sim 590 \mathrm{~nm}$ ) directly into the ${ }^{1} \mathrm{D}_{2}$ state. One of the excited ion in the ${ }^{1} \mathrm{D}_{2}$ state 
transfers its excitation energy to its neighboring second excited ion in the same state and returns to the ground state. The second excited ion after receiving the additional energy is excited upward to the ${ }^{3} \mathrm{P}_{\mathrm{J}}$ state; the radiative relaxation from the ${ }^{3} \mathrm{P}_{0}$ level gives an intense blue emission at $\sim 480 \mathrm{~nm}$ attributed to the ${ }^{3} \mathrm{P}_{0} \rightarrow{ }^{3} \mathrm{H}_{4}$ transition. The phenomenon of the energy-transfer process containing a pair of $\mathrm{Pr}^{3+}$ ions can be given as,

2 photons (2hv) +2 ions in the ${ }^{3} \mathrm{H}_{4}$ (ground) state $\rightarrow{ }^{1} \mathrm{D}_{2}+{ }^{1} \mathrm{D}_{2} \rightarrow{ }^{3} \mathrm{P}_{\mathrm{J}}+{ }^{1} \mathrm{G}_{4} \rightarrow{ }^{3} \mathrm{P}_{0}+{ }^{3} \mathrm{H}_{4}+$ phonons.

The temporal evolution of the emission at $\sim 480 \mathrm{~nm}$ shows rise and decay times which are illustrated in Fig. 5 for all the doped samples. From this figure, it is clear that the rise and decay times depend upon the concentration of the praseodymium ions. The time dependence of the upconversion intensity can be expressed as,

$$
I_{U P} \alpha\left[\exp \left(-t / \tau_{r}\right)-\exp \left(-t / \tau_{d}\right)\right]
$$

where ' $\tau_{\mathrm{r}}^{\prime}$ and ' $\tau_{\mathrm{d}}$ ' are the rise and decay times of the upconverted fluorescence respectively. The rise and decay times is observed to decrease as the concentration of the rare-earth ions increases from $0.2 \mathrm{~mol} \%$ to $1.0 \mathrm{~mol} \%$, which also confirms that energy transfer is the dominant mechanism among the excited and its neighboring unexcited ions.
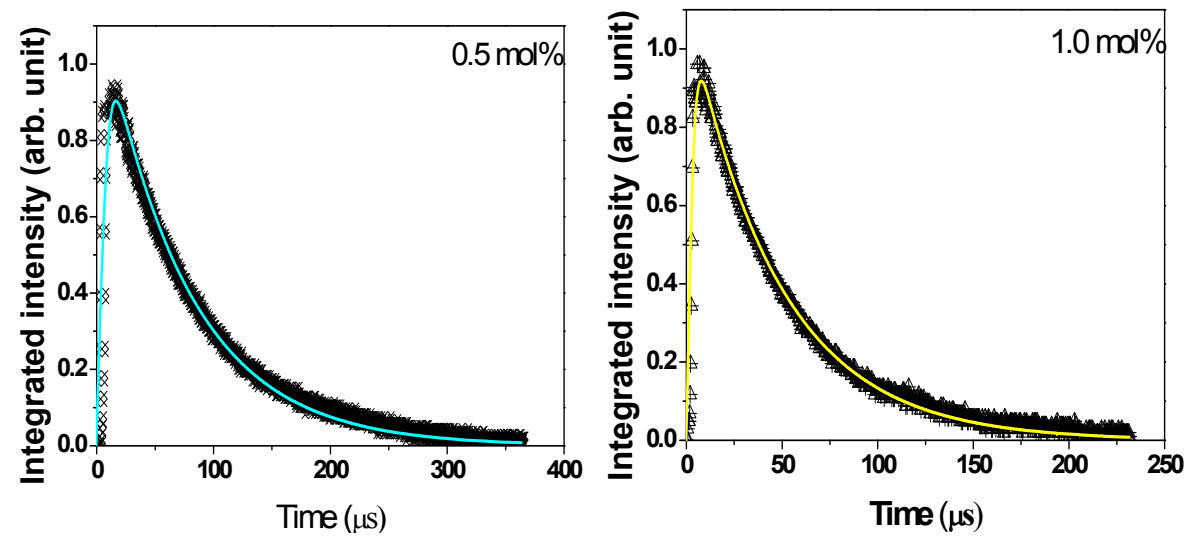

Fig. 5. Temporal evolution of upconversion emission at $\sim 480 \mathrm{~nm}$. Reprinted with permission from ref. (Rai, 2009), Copyright 2009, Springer.

\section{Energy transfer process between donors and acceptors}

Energy transfer among the donors and acceptors modifies the fluorescence decay and the dynamical behavior of the emission at $\sim 680 \mathrm{~nm}$ and can be described by Inokuti- Hirayama (I-H) model [Inokuti et al., 1965]. According to the I - H model,

$$
I(t)=I_{0} \exp \left\{-t / \tau_{0}-\Gamma(1-3 / S) C / C_{0}\left(t / \tau_{0}\right)^{3 / S}\right\}
$$

or

$$
I(t)=I_{0} \exp \left\{-t / \tau_{0}-P(t)\right\}
$$


where

$$
P(t)=\Gamma(1-3 / S) C / C_{0}\left(t / \tau_{0}\right)^{3 / S}
$$

and ' $\tau_{0}$ ' is the lifetime of the isolated ions in absence of the energy transfer. $C$ and $C_{0}$ are the concentration of the rare earth ions and the critical concentration respectively. ' $\Gamma$ ' is a gamma function. $P(t)$, the transfer function that assumes different forms at different concentrations of rare earth ions, origin of the interaction between the ions and time range [Inokuti et al., 1965]. $\mathrm{P}(\mathrm{t})$ involves the contributions due to the energy transfer (ET) processes taking place for the frequency upconversion and ET between donors and acceptors that contributes to the fluorescence emission. The temporal behavior of the ${ }^{1} \mathrm{D}_{2} \rightarrow 3 \mathrm{H}_{5}$ transition peaking at $\sim 680 \mathrm{~nm}$ as a function of praseodymium ion concentrations was monitored. The radiative lifetime observed for fluorescence emission at $\sim 680 \mathrm{~nm}$ is $\sim 250 \mu$ s at $\sim 0.01 \mathrm{~mol} \%$ for which no upconversion emission is seen. It is found that the decay curve deviates from its pure exponential shape and lifetime of the ${ }^{1} \mathrm{D}_{2}$ level decreases with increasing concentration. This indicates that the fast diffusion process should be ignored. Therefore, the static transfer process is the dominant mechanism for energy transfer within the concentration range of our samples. The decay time $\left(\tau_{D}\right)$ for the ${ }^{1} \mathrm{D}_{2}$ level can be written as,

$$
1 / \tau_{D}=W_{\text {Rad }}+W_{N R} \text {, where radiative decay rate }\left(W_{R a d}\right)=1 / \tau_{0}
$$

$\mathrm{W}_{\mathrm{NR}}$, the nonradiative relaxation rate (which involves the multiphonon emission and energy transfer among the rare earth ions) and its value determined for all doped samples using equation (3) are $\sim 1.5 \times 10^{3}, \sim 5.7 \times 10^{3}$ and $\sim 22.5 \times 10^{3} \mathrm{~Hz}$ respectively. A plot for $W_{\mathrm{NR}}$ versus concentration shows a quadratic behavior with a slope $\sim 1.7 \pm 0.1<2$. This difference is due to the emission of multiple phonons through nonradiative relaxation, employing that two rare earth ions are involved in the energy transfer process.

At longer times the acceptors at large distances are taken into account so according to $\mathrm{I}-\mathrm{H}$ Model [Inokuti et al., 1965],

$$
P(t)=\Gamma(1-3 / S) C / C_{0}\left(t / \tau_{0}\right)^{3 / S}=\beta \tau^{3 / S}
$$

where $\beta=\Gamma(1-3 / S) C / C_{0}\left(1 / \tau_{0}\right)^{3 / S}$, and $S=6,8$ and 10 for dipole-dipole, dipolequadrupole and quadrupole-quadrupole type interactions respectively. ' $\beta$ ' is function of radiative lifetime of isolated ions, critical concentration (at which the energy transfer rate for an isolated ion pair is equal to the spontaneous decay rate of the donor). Moreover, in order to get the information about the type of the interactions involved, a log-log plot for $\mathrm{P}(\mathrm{t})$ versus time $(t)$ by extracting the exponential factor $\exp \left(-\tau / \tau_{0}\right)$ from equation (2) was made and found best fit with slope $3 / S \approx 0.51 \pm 0.01$ (i.e. $S \approx 6$ ) for all the doped samples, thereby indicating the interaction to be of dipole-dipole type (Fig 6).

Let $\mathrm{N}_{1}, \mathrm{~N}_{2}$ be the populations in the pair states $|1\rangle=\left|{ }^{1} \mathrm{D}_{2},{ }^{1} \mathrm{D}_{2}\right\rangle$ and $|2\rangle=\left|{ }^{3} \mathrm{P}_{0},{ }^{3} \mathrm{H}_{4}\right\rangle$ respectively and $\gamma_{1}, \gamma_{2}$ represent respectively the relaxation rates of state $|1\rangle$ due to all possible mechanism except the transfer to state $|2\rangle$ and the total radiative relaxation rate from state $|2\rangle$. If $W_{12}$ is the energy transfer rate from state $|1\rangle$ to state $|2\rangle$, the temporal evolution after excitation of the initial state of the pair and of its final fluorescent state may be given as [Pelle et al., 1993], 


$$
\begin{aligned}
& \frac{d N_{1}}{d t}=-\left[\gamma_{1}+W_{12}\right] N_{1} \\
& \frac{d N_{2}}{d t}=W_{12} N_{1}-\gamma_{2} N_{2}
\end{aligned}
$$

The solutions of the above equations are

$$
\begin{gathered}
N_{1}(t)=N_{1}(0) e^{-\left(\gamma_{1}+W_{12}\right) t} \\
N_{2}(t)=\frac{N_{1}(0) W_{12}}{\gamma_{1}-\gamma_{2}+W_{12}}\left(e^{-\gamma_{2} t}-e^{-\left(\gamma_{1}+W_{12}\right) t}\right)
\end{gathered}
$$

In order to compare the observed decay and rise times, it is assumed that the two rates $\left(\gamma_{1}+\right.$ $W_{12}$ ) and $\gamma_{2}$ are smaller than $\tau_{r}{ }^{-1}$, while $\tau_{d}{ }^{-1}$ corresponds to the smaller rate.

Here the observed decay times are longer than the actual lifetime of the ${ }^{3} \mathrm{P}_{0}$ level $(\sim 8.9 \mu \mathrm{s})$. On comparing the equation (1) with equation (8), it can be seen that $\tau_{\mathrm{r}}^{-1}$ and $\tau_{\mathrm{d}}{ }^{-1}$ corresponds to $\gamma_{2}$ and $\left(\gamma_{1}+W_{12}\right)$ respectively. Therefore, the value of $W_{12}$ can be determined using the relation, $\tau_{d^{-1}}=W_{12}+\gamma_{1}$ and observed to be large $(\approx 1075 \mathrm{~Hz})$ compared to the other fluoride based host matrices.
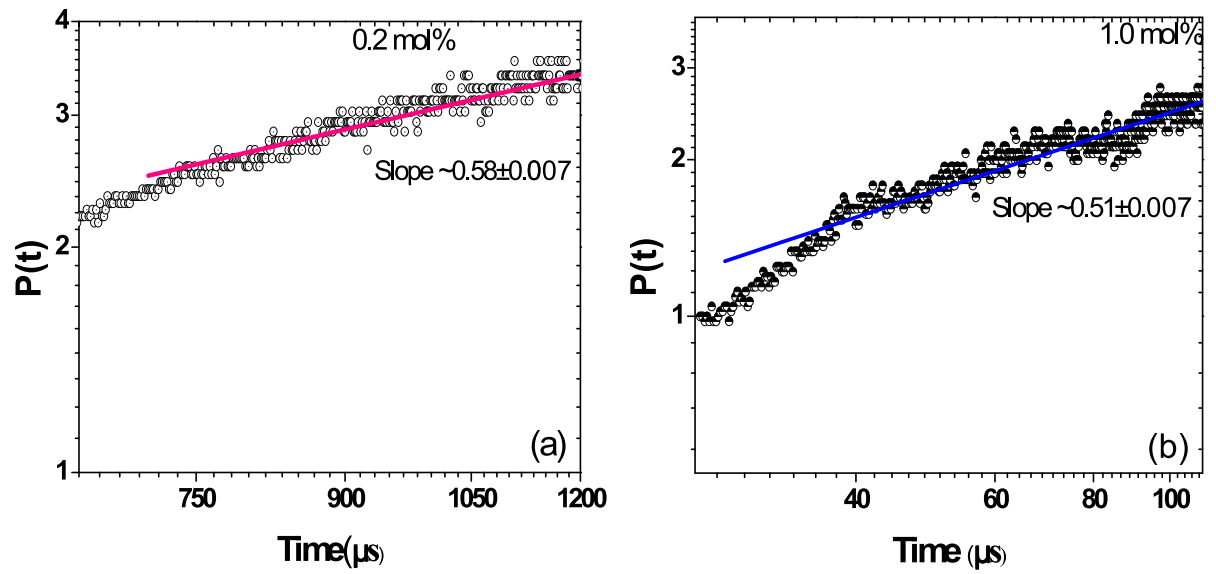

Fig. 6. $\log -\log$ plot of $\mathrm{P}(\mathrm{t})$ versus $t$. Reprinted with permission from ref. (Rai, 2009), Copyright 2009, Springer.

Orange to blue frequency upconversion in $\mathrm{Pr}^{3+}$ doped $\mathrm{TeO}_{2}-\mathrm{ZnO}$ and chalcogenide $\left(\mathrm{Ga}_{10} \mathrm{Ge}_{25} \mathrm{~S}_{65}\right)$ glasses containing silver nanoparticles under excitation with a nanosecond laser operating at $\sim 590 \mathrm{~nm}$, in resonance with the ${ }^{3} \mathrm{H}_{4} \rightarrow{ }^{1} \mathrm{D}_{2}$ transition has been studied [Rai et al., 2008; Rai et al., 2008]. The absorption spectra of the GGSPr sample with and without metallic nanoparticles annealed for different time intervals have been shown in Fig 7. The absorption bands associated with the $\mathrm{Pr}^{3+}$ transitions from the ground state $\left({ }^{3} \mathrm{H}_{4}\right)$ to different excited states viz. ${ }^{3} \mathrm{P}_{2},{ }^{3} \mathrm{P}_{1},{ }^{3} \mathrm{P}_{0}$ and ${ }^{1} \mathrm{D}_{2}$ and a feature at $\sim 472 \mathrm{~nm}$ attributed to surface plasmon resonance (SPR) of the NPs are observed. The SPR wavelength calculated using Mie theory 


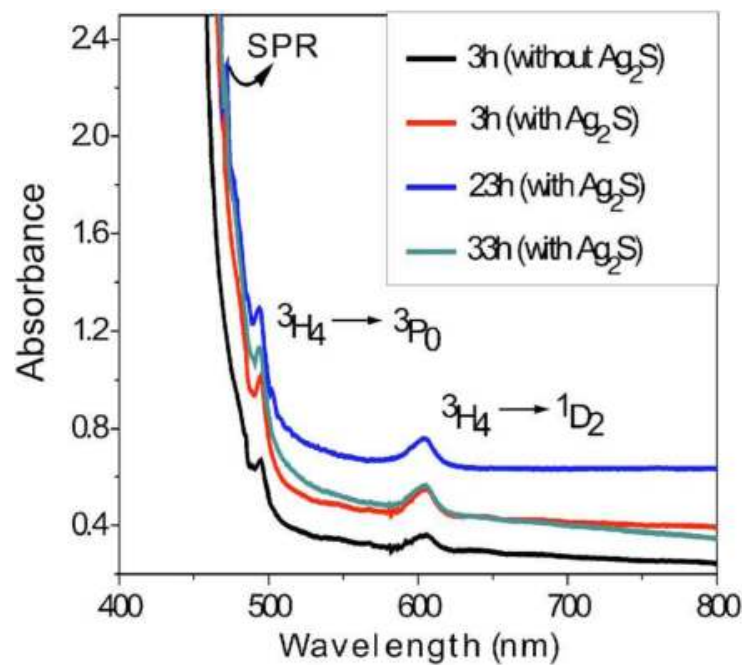

Fig. 7. Absorption spectra of the GGSPr sample (with and without metallic nanoparticles) for different annealing times as indicated in the legend. Reprinted with permission from ref. (Rai et al., 2008), Copyright 2008, American Institute of Physics.

[Prasad, 2004], considering spherical particles, the dielectric function of bulk silver [Palik, 1985] and the glass refractive index, is $\sim 485 \mathrm{~nm}$. This result shows a reasonable agreement with the experimental value since the effect of the metal glass interface is not considered in the calculations neither the nanoparticles shape. The amplitude of the band at $\sim 472 \mathrm{~nm}$ increases with increasing the concentration of nanoparticles which grows up for heattreatment time of $\sim 23$ hour $(\mathrm{h})$. For a heat treatment time longer than $23 \mathrm{~h}$, a reverse trend is observed for the concentration. No shift of the band peaking at $\sim 472 \mathrm{~nm}$ was observed for different annealing times. The excited $\mathrm{Pr}^{3+}$ ions exchange energy in presence of the nanoparticles, originating efficient conversion from orange to blue. The enhancement in the intensity of the upconversion luminescence corresponding to the ${ }^{3} \mathrm{P}_{0} \rightarrow{ }^{3} \mathrm{H}_{4}$ transition of $\mathrm{Pr}^{3+}$ ions, is found to be due to the proximity between the surface plasmon band and the $\left[{ }^{3} \mathrm{P}_{\mathrm{J}}\right.$ $\left.(\mathrm{J}=0,1,2) ;{ }^{1} \mathrm{I}_{6}\right)$ manifold. The intensity of the emission corresponding to the ${ }^{1} \mathrm{D}_{2} \rightarrow{ }^{3} \mathrm{H}_{5}$ transition was not affected by the presence of the metallic nanoparticles because the $1 \mathrm{D}_{2}$ multiplet is located far from the surface plasmon band (Fig. 8).

$\mathrm{Pr}^{3+}$ doped samples without silver were heat treated for different time intervals, but no variation in the luminescence intensity was observed, indicating that the presence of nanoparticles is essential to obtain enhanced emission. No evidence of change in the glass structure neither nucleation of nanoparticles due to the influence of the laser was observed. This is understood considering that the laser pulses have low energy and the pulse repetition rate $(\sim 5 \mathrm{~Hz})$ is small. This result confirms that the enhancement of the upconversion intensity in other samples is attributed to the large local field acting on the emitting ions due to presence of the metallic nanoparticles and not due to changes in the glass structure. On the other hand, quenching was also observed for samples heat treated for longer times, which indicates that ET occurs from the $\mathrm{Pr}^{3+}$ ions to the metallic 
nanoparticles. This result is important in the sense that it demonstrates that there is an optimum heat-treatment time of samples to observe enhanced frequency UC due to nucleation of metallic nanoparticles.

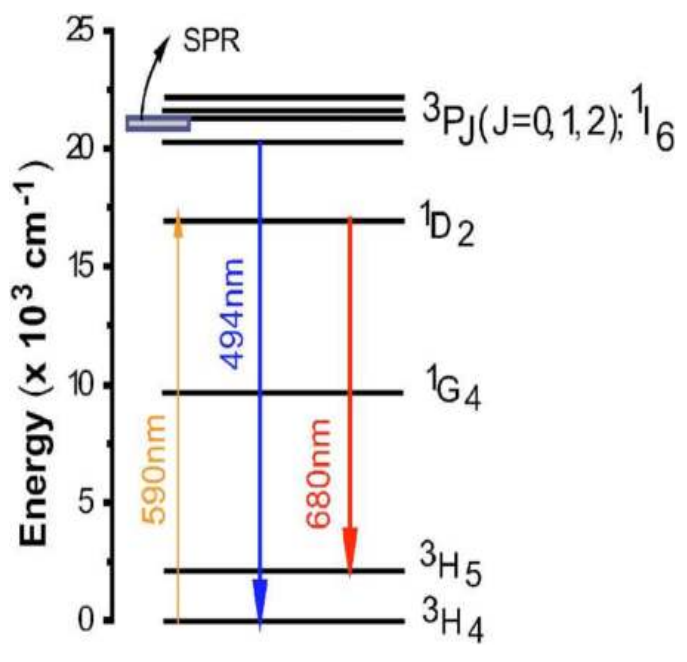

Fig. 8. Simplified energy level diagram of $\operatorname{Pr}^{3+}$. Reprinted with permission from ref. (Rai et al., 2008), Copyright 2008, American Institute of Physics.

\subsection{Frequency upconversion in $\mathrm{Nd}^{3+}$ doped glasses}

Optical spectroscopy and upconversion luminescence in $\mathrm{Nd}^{3+}$ doped $\mathrm{Ga}_{10} \mathrm{Ge}_{25} \mathrm{~S}_{65}$ glass has been reported [Rai et al., 2009]. The mechanisms leading to the upconversion emissions upon nonresonant excitation at $\sim 1.064 \mathrm{~mm}$ in the $\mathrm{Nd}^{3+}$ doped chalcogenide glass corresponding to the green, orange, and red regions as well as the dynamics of the process have been investigated. The samples were prepared by the melt-quenching method. The absorption spectrum of the $\mathrm{Nd}^{3+}(0.25 \mathrm{~mol} \%)$ doped chalcogenide glass sample contains several absorption bands at $\sim 884, \sim 806, \sim 795, \sim 750, \sim 682, \sim 594$, and $\sim 532 \mathrm{~nm}$ corresponding to the transitions from the ground state $\left({ }^{4} \mathrm{I}_{9 / 2}\right)$ to the ${ }^{4} \mathrm{~F}_{3 / 2},{ }^{4} \mathrm{~F}_{5 / 2},{ }^{2} \mathrm{H}_{9 / 2}, 4 \mathrm{~F}_{7 / 2},{ }^{4} \mathrm{~F}_{9 / 2},{ }^{4} \mathrm{~F}_{5 / 2}$, and ${ }^{4} \mathrm{G}_{7 / 2}$ excited states respectively. The spectra of other concentrated samples are similar but the intensity of the absorption bands depends linearly on the concentration of the $\mathrm{Nd}^{3+}$ ions.

The upconversion spectrum observed under infrared excitation at $\sim 1.064 \mu \mathrm{m}$ is shown in Fig. 9. Three luminescence bands are observed at $\sim 535, \sim 600$, and $\sim 670 \mathrm{~nm}$ corresponding to the ${ }^{4} \mathrm{G}_{7 / 2} \rightarrow{ }^{4} \mathrm{I}_{9 / 2}, \quad\left[{ }^{4} \mathrm{G}_{7 / 2} \rightarrow{ }^{4} \mathrm{I}_{11 / 2} ; \quad{ }^{4} \mathrm{G}_{5 / 2} \rightarrow{ }^{4} \mathrm{I}_{9 / 2}\right], \quad$ and $\quad\left[{ }^{4} \mathrm{G}_{7 / 2} \rightarrow{ }^{4} \mathrm{I}_{13 / 2} ; \quad{ }^{4} \mathrm{G}_{5 / 2} \rightarrow{ }^{4} \mathrm{I}_{11 / 2}\right] \quad$ transitions respectively. The upconversion intensity versus pump power as well as concentration of the $\mathrm{Nd}^{3+}$ has been observed to follow a quadratic dependence, indicating that two laser photons and two $\mathrm{Nd}^{3+}$ ions contribute to the emission of each upconversion photon. To obtain additional information about the upconversion process the temporal evolution of the ${ }^{4} \mathrm{G}_{7 / 2} \rightarrow{ }^{4} \mathrm{I}_{9 / 2}$ transition peaking at $\sim 535 \mathrm{~nm}$ was studied. The luminescence signal shows 
decay times of $\sim 53.4 \pm 0.4,32.6 \pm 0.3$ and $18.0 \pm 0.1 \mu$ s for the $\mathrm{Nd}^{3+}$ concentrations of $0.05,0.10$, and $0.25 \mathrm{~mol} \%$, respectively. Since the radiative lifetime $\tau_{R}$ of the ${ }^{4} \mathrm{G}_{7 / 2}$ level is $\sim 81.23 \mu \mathrm{s}$. The measured decay times indicate a strong interaction among the $\mathrm{Nd}^{3+}$ ions. Since the energy difference $\left[E\left({ }^{4} G_{7 / 2}\right)-E\left({ }^{4} G_{5 / 2}\right)\right]$ has about the same value as $\left[E\left({ }^{4} I_{11 / 2}\right)-E\left({ }^{4} I_{9 / 2}\right)\right]$ (Fig. 10). Then the decrease in the lifetime of level ${ }^{4} \mathrm{G}_{7 / 2}$ is attributed to the cross-relaxation process $\left({ }^{4} \mathrm{G}_{7 / 2} ;{ }^{4} \mathrm{I}_{9 / 2}\right) \rightarrow\left({ }^{4} \mathrm{G}_{5 / 2} \rightarrow{ }^{4} \mathrm{I}_{11 / 2}\right)$. The actual lifetime is related to the crossrelaxation rate by $\tau=\tau_{R} /\left(1+W_{C R} \tau_{R}\right)$ with $W_{C R}$ being equal to $\sim 6.4 \times 10^{3} \mathrm{~Hz}\left(0.05 \mathrm{~mol} \% \mathrm{Nd}^{3+}\right), 18 \times 10^{3}$ $\mathrm{Hz}\left(0.1 \mathrm{~mol} \% \mathrm{Nd}^{3+}\right)$, and $43 \times 10^{3} \mathrm{~Hz}\left(0.25 \mathrm{~mol} \% \mathrm{Nd}^{3+}\right)$.

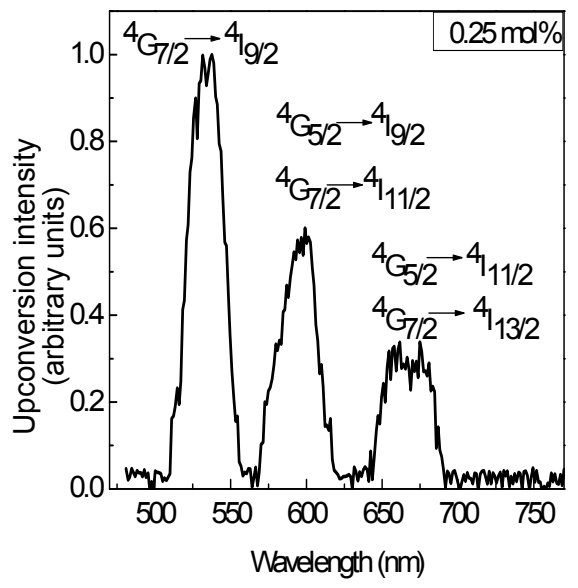

Fig. 9. Frequency upconversion spectrum for excitation using a laser operating at $1.064 \mu \mathrm{m}$. Reprinted with permission from ref. (Rai et al., 2009), Copyright 2009, American Institute of Physics.

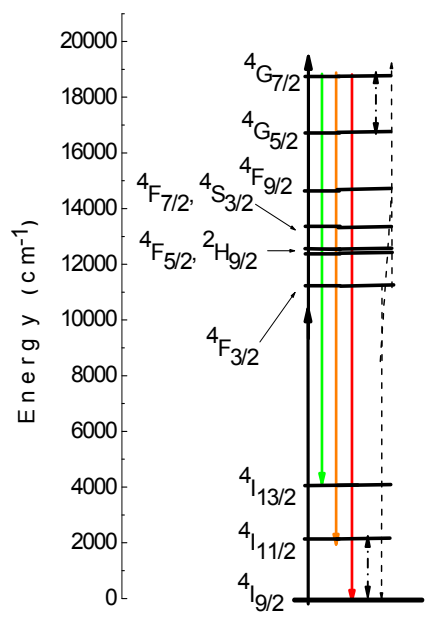

Fig. 10. Simplified energy level scheme for the $\mathrm{Nd}^{3+}$ ions. Reprinted with permission from ref. (Rai et al., 2009), Copyright 2009, American Institute of Physics. 
To understand the origin of the upconversion luminescence there are three possible excitation pathways. As the laser frequency ' $\omega_{L}$ ' is off - resonance with the $\mathrm{Nd}^{3+}$ transitions starting from the ground state $\left({ }^{4} \mathrm{I}_{9 / 2}\right)$. However, two-photon absorption (TPA) is resonant for a transition from ground state to the ${ }^{4} \mathrm{G}_{7 / 2}$ state. The upconversion luminescence intensity in this case would be quadratic with the laser intensity and would vary linearly with the $\mathrm{Nd}^{3+}$ concentration.

Another possibility would be due to a one-photon transition to the $4 \mathrm{~F}_{3 / 2}$ level followed by energy transfer (ET) between pairs of excited $\mathrm{Nd}^{3+}$ ions. As a result of this process two ions excited to the ${ }^{4} \mathrm{~F}_{3 / 2}$ level may interact and exchange energy in such way that one decay to the ground state and the other is promoted to the ${ }^{4} \mathrm{G}_{7 / 2}$ level from where it decays radiatively to lower lying levels. However, although this process of energy transfer has been observed in other glasses [Rai, 2009; Rai et al., 2008]. In the present case this process is not expected to be more efficient than the TPA process discussed above because the one-photon frequency detuning for the electronic transition ${ }^{4} \mathrm{I}_{9 / 2} \rightarrow{ }^{4} \mathrm{~F}_{3 / 2}$ is $\approx 1500 \mathrm{~cm}^{-1}$. The absorption has to be phonon-assisted and the corresponding probability is small. Another possibility to excite the ${ }^{4} \mathrm{~F}_{3 / 2}$ level would be a resonant one-photon transition originating from the ${ }^{4} \mathrm{I}_{11 / 2}$ level. However the population in the ${ }^{4} \mathrm{I}_{11 / 2}$ level is small at $\sim 300 \mathrm{~K}$. In both cases the UC luminescence intensity would present a quadratic dependence with the laser intensity and with the $\mathrm{Nd}^{3+}$ concentration.

\section{Acknowledgements}

Author is grateful to University Grants Commission (UGC) and Department of Science \& Technology (DST), New Delhi, India for the financial assistance.

\section{References}

Babu, P.; Jayasanker C. K., 'Optical spectroscopy of $\mathrm{Eu}^{3+}$ ions in lithium borate and lithium fluoroborate glasses', Physica B, 279 (2000) 262-281.

Balda, R.; Fernández, J.; Adam, J. L.; Mendioroz, A; Arriandiaga, M. A., Energy transfer and frequency upconversion in $\mathrm{Pr}^{3+}$-doped fluorophosphate glass', J. Non-Crystalline Solids, 256-257 (1999) 299-303.

Born, M.; Wolf, E., Principles of optics (Cambridge University Press, Cambridge, 1999).

Dieke, G. H.; Crosswhite, H. M., Spectra and energy levels of rare earth ions in crystals, Inter Science, New York, 1968.

Digonnet, M.J.F., 'Rare earth doped fiber lasers and amplifier', (Dekker, New York, 1993).

Dumbaugh, W. H.; Lapp, J. C., Heavy-Metal Oxide Glasses', J. Am. Ceramic Soc., 75 (1992) 2315-2326.

Edward D. Palik, Handbook of Optical Constants of Solids (Academic, New York, 1985).

Ebendroff, H.; Priems, H.; Ehert, D., 'Spectroscopic properties of $\mathrm{Eu}^{3+}$ and $\mathrm{Tb}^{3+}$ ions for local structure investigations of fluoride phosphate and phosphate glasses', J. Non-Cryst. Solids, 208 (1996) 205-216.

El-Mallawany, R. A. H., Tellurite glasses handbook-Physical properties and data (CRC, Boca Raton, FL, 2001).

Ganem, J.; Dennis, W.M.; Yen, W.M., ‘One-color sequential pumping of the $4 \mathrm{f} 5 \mathrm{~d}$ bands in Pr-doped yttrium aluminum garnet', J. Lumin., 54 (1992) 79-87. 
Hussain, N. S.; Buddhudu, V. S., 'Absorption and photoluminescence spectra of $\mathrm{Sm}^{3+}: \mathrm{TeO}_{2}-$ $\mathrm{B}_{2} \mathrm{O}_{3}-\mathrm{P}_{2} \mathrm{O}_{5}-\mathrm{Li}_{2} \mathrm{O}$ glass', Mater. Res. Bull., 35 (2000) $703-709$.

Inokuti, M.; Hirayama, F., 'Influence of energy transfer by the exchange mechanism on donor luminescence', J. Chem. Phys., 43 (1965) 1978 (1-12).

Jackson, S. D., 'Continuous wave 2.9 um dysprosium doped fluoride fiber laser', Appl. Phys. Lett., 83 (2003) 1316-1318.

Kaminskii, A.A., Laser crystals, second ed., Springer-Verlag, Berlin, 1990.

Kaplyanskii, A. A.; Macfarlane, R. M., 'Spectroscopy of Solids containing Rare Earth Ions', (North-Holland, New York, 1987).

Kassab, L. R. P.; Araújo C. B. de; Kobayashi, R. A.; Pinto R. A.; Silva, D. M. da, 'Influence of silver nanoparticles in the luminescence efficiency of $\mathrm{Pr}^{3+}$-doped tellurite glasses', J. Appl. Phys., 102 (2007) 103515 (1-4).

Kenyon, A. J., 'Recent developments in rare-earth doped materials for optoelectronics', Progr. Quantum Electron., 26 (2002) 225-284.

Kumar, G. M.; Rao, D. N.; Agarwal, G. S., 'Experimental studies of spontaneous emission from dopants in an absorbing dielectric', Opt. Lett., 30 (2005) 732-734.

Lezama, A.; Leite, J. R. Rios; Araújo, C. B. de, 'Triad spectroscopy via ultraviolet upconversion in $\operatorname{Pr}^{3+}: \mathrm{LaF}_{3}{ }^{\prime}$, Phys. Rev. B, 32 (1985) 7139-7142.

Lin, H.; Pun, E. Y. B.; Huang, L. H.; Liu, X. R., ‘Optical and luminescence properties of $\mathrm{Sm}^{3+}$ doped cadmium-aluminum-silicate glasses', Appl. Phys. Lett., 80 (2002) 2642 (1-3).

Luis E.E. de Araujo, Gomes, A.S.L.; Araujo, Cid B. de; Messaddeq, Y.; Florez, A.; Aegerter, M. A., 'Frequency upconversion of orange light into blue light in $\mathrm{Pr}^{3+}$-doped fluoroindate glasses', Phys. Rev. B, 50 (1994) 16219-16223.

Mohanty, D. K.; Rai, V. K.; Dwivedi, Y.; Rai, S. B., Enhancement of upconversion intensity in $\mathrm{Er}^{3+}$ doped tellurite glass in presence of $\mathrm{Yb}^{3+}$. Appl. Phys. B, 104 (2011) 233-236.

Mujaji, M.; Jones, G.D.; Syme, R.W.G., 'Site-Selective Spectroscopy of $\mathrm{Ho}^{3+}$ Ions in $\mathrm{CsCdBr}_{3}$ Crystals' Phys. Rev. B, 48 (1993) 710-725.

Nachimuthu, P.; Jagnnathan, R.; Nirmal Kumar, V.; Rao, D. N., 'Absorption and emission spectral studies of $\mathrm{Sm}^{3+}$ and $\mathrm{Dy}^{3+}$ ions in $\mathrm{PbO}^{3} \mathrm{PbF}_{2}$ glasses', J. Non-Cryst. Solids, 217 (1997) 215-223.

Nageno, Y.; Takabe, H.; Moringama, K.; Izumitani, T., 'Effect of modifier ions on fluorescence and absorption of $\mathrm{Eu}^{3+}$ in alkali and alkaline earth silicate glasses', J. Non-Cryst. Solids, 169 (1994) 288-294.

Oliveria, A.S.; Araujo, M.T. de; Gouveia-Neto, A.S.; Medeiros Neto, J.A.; Sombra, A.S.B.,' Frequency upconversion in $\mathrm{Er}^{3+} / \mathrm{Yb}^{3+}$-codoped chalcogenide glass', Appl. Phys. Lett., 72 (1998) 753 (1-3).

Pacheco, Elio M.; Araujo, Cid B. De, 'Frequency up-conversion in a borate glass doped with $\operatorname{Pr}^{3+}{ }^{\prime}$, Chemical Physics Letters., 148 (1988) 334-336.

Parker, J. M., 'Fluoride Glasses', Annu. Rev. of Mater. Sci., 19 (1989) 21-41.

Pelle, F.; Glodner, Ph., 'Pair processes in $\mathrm{CsCdBr}_{3}: \mathrm{Er}^{3+}$ : A study by up-conversion and excited-state absorption of efficient UV and blue anti-Stokes emissions', Phys. Rev. B, 48 (1993) 9995-10010

Prasad, P. N., Nanophotonics (Wiley, New York, 2004).

Rai, A.; Rai, V.K., 'Optical properties and upconversion in $\mathrm{Pr}^{3+}$ doped in Aluminium, Barium, Calcium Fluoride glass-I', Spectrochim. Acta A, 63 (2006) 27-31. 
Rai, V. K., 'Local field effect of the host matrix on the decay time of doped emitters', Appl. Phys. B, 100 (2010) 871-874.

Rai, V. K., 'Temperature sensors and optical sensors', Appl. Phys. B, 88 (2007) 297-303.

Rai, V. K.; Araújo, C. B. de; Ledemi, Y.; Bureau, B.; Poulain, M.; Zhang, X. H.; Messaddeq, Y., ' Frequency upconversion in a $\mathrm{Pr}^{3+}$ doped chalcogenide glass containing silver nanoparticles', J. Appl. Phys., 103 (2008) 103526 (1-4).

Rai, V. K.; Araújo, Cid B. de; Ledemi, Y.; Bureau, B.; Poulain, M.; Messaddeq, Y.,' Optical spectroscopy and upconversion luminescence in $\mathrm{Nd}^{3+}$ doped $\mathrm{Ga}_{10} \mathrm{Ge}_{25} \mathrm{~S}_{65}$ glass', J. Appl. Phys., 106 (2009) 103512 (1-5).

Rai, V. K.; Araujo, Cid B. de; Menezes, L. de, 'Two photon absorption in $\mathrm{TeO}_{2}-\mathrm{PbO}$ glasses excited at 532 and 590nm', Appl. Phys. A, 91 (2008) 441-443.

Rai, V. K.; Kumar, K.; Rai, S.B., 'Upconversion in $\operatorname{Pr}^{3+}$ doped tellurite glass', Optical Materials, 29 (2007) 873-878.

Rai, V. K.; Menezes, L. de S.; Araújo, C. B. de,' Infrared-to-green and blue upconversion in $\mathrm{Tm}^{3+}$-doped $\mathrm{TeO}_{2}-\mathrm{PbO}$ glass', J. Appl. Phys., 103 (2008) 053514 (1-4).

Rai, V. K.; Menezes, L. de S.; Araujo, C. B. de; Kassab, L. R. P.; Silva, D. M. da; Kobayashi, R. A., 'Surface-plasmon-enhanced frequency upconversion in $\mathrm{Pr}^{3+}$ doped telluriumoxide glasses containing silver nanoparticles', J. Appl. Phys., 103 (2008) 93526.

Rai, V. K.; Rai, S. B.; Rai, D.K., 'Optical studies of Dy ${ }^{3+}$ doped tellurite glass: Observation of yellow-green upconversion', Optics Communications, 257 (2006) 112-119.

Rai, V.K., 'Upconversion due to energy transfer involving $\mathrm{Pr}^{3+}$ ions in pairs', Appl. Phys. B, 95 (2009) 329-333.

Reisfield, R., 'Spectra and energy transfer of rare earths in inorganic glasses', Structure and Bonding, 13 (1973) 53-98.

Sai Sudha, M. B.; Ramakrishna, J., 'Effect of host glass on the optical absorption properties of $\mathrm{Nd}^{3+}, \mathrm{Sm}^{3+}$, and $\mathrm{Dy}^{3+}$ in lead borate glasses', Phys. Rev. B, 53 (1996) 6186-6196.

Savage, J. A., 'Materials for infrared fiber optics', Mater. Sci. Rep., 2 (1987) 99-138.

Silva, D. M. da; Kassab, L. R. P.; Lüthi, S. R.; Araújo, C. B. de; Gomes, A. S. L.; Bell, M. J. V., 'Frequency upconversion in $\mathrm{Er}^{3+}$ doped $\mathrm{PbO}-\mathrm{GeO}_{2}$ glasses containing metallic nanoparticles', Appl. Phys. Lett., 90 (2007) 81913 (1-3).

Smart, R.G.; Hanna, D.C.; Tropper, A.C.; Davey, S.T.; Carter, S.F.; Szebesta, D., 'CW room temperature upconversion lasing at blue, green and red wavelengths in infraredpumped $\mathrm{Pr}^{3+}$-doped fluoride fibre', Electron. Lett., 127 (1991) 1307-1309.

Snoeks, E.; Lagendijk, A.; Polman, A., 'Measuring and modifying the spontaneous emission rate of erbium near an interface', Phys. Rev. Lett., 74 (1995) 2459-2462.

Tripathi, G.; Rai, V. K.; Rai, D.K; Rai, S.B., 'Upconversion in $\mathrm{Er}^{3+}$ doped $\mathrm{Bi}_{2} \mathrm{O}_{3}-\mathrm{Li}_{2} \mathrm{O}-\mathrm{BaO}-$ PbO tertiary glass' Spectrochimica Acta Part A, 66 (2007) 1307-1311.

Tripathi, G.; Rai, V. K.; Rai, S. B., 'Optical properties of $\mathrm{Sm}^{3+}$ : $\mathrm{CaO}-\mathrm{Li}_{2} \mathrm{O}-\mathrm{B}_{2} \mathrm{O}_{3}-\mathrm{BaO}$ glass and codoped $\mathrm{Sm}^{3+}: \mathrm{Eu}^{3+}$. Appl. Phys. B, 84 (2006) 459-464.

Tripathi, G.; Rai, V. K.; Rai, S. B., 'Spectroscopic studies of Eu' ${ }^{3+}$ doped calibo glass: Effect of the addition of barium carbonate, energy transfer in the presence of $\mathrm{Sm}^{3+}{ }^{\prime}$, Optics Communications, 264 (2006) 116-122.

Victor, T.K.; Raffaella, R.; Maurizio, M.; Maurizio, F., in: S. Jiang (Ed.), Rare earth doped materials and devices VI, Proc. SPIE, 4645 (2002) 174-182.

Yamane, M.; Y. Ashara, Glasses for Photonics (Cambridge University Press, Cambridge, England, 2000). 


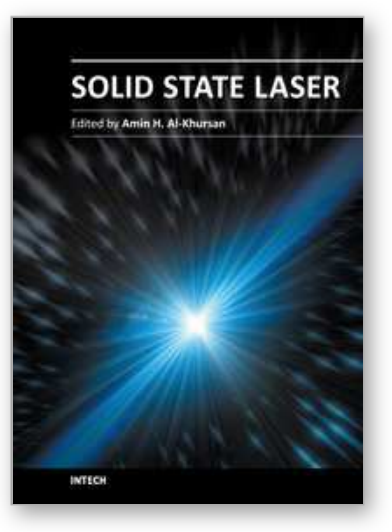

\author{
Solid State Laser \\ Edited by Prof. Amin Al-Khursan
}

ISBN 978-953-51-0086-7

Hard cover, 252 pages

Publisher InTech

Published online 17, February, 2012

Published in print edition February, 2012

This book deals with theoretical and experimental aspects of solid-state lasers, including optimum waveguide design of end pumped and diode pumped lasers. Nonlinearity, including the nonlinear conversion, up frequency conversion and chirped pulse oscillators are discussed. Some new rare-earth-doped lasers, including double borate and halide crystals, and feedback in quantum dot semiconductor nanostructures are included.

\title{
How to reference
}

In order to correctly reference this scholarly work, feel free to copy and paste the following:

Vineet Kumar Rai (2012). Frequency Upconversion in Rare Earth Ions, Solid State Laser, Prof. Amin AlKhursan (Ed.), ISBN: 978-953-51-0086-7, InTech, Available from: http://www.intechopen.com/books/solidstate-laser/frequency-upconversion-in-rare-earth-ions

\section{INTECH}

open science | open minds

\author{
InTech Europe \\ University Campus STeP Ri \\ Slavka Krautzeka 83/A \\ 51000 Rijeka, Croatia \\ Phone: +385 (51) 770447 \\ Fax: +385 (51) 686166 \\ www.intechopen.com
}

\author{
InTech China \\ Unit 405, Office Block, Hotel Equatorial Shanghai \\ No.65, Yan An Road (West), Shanghai, 200040, China \\ 中国上海市延安西路65号上海国际贵都大饭店办公楼 405 单元 \\ Phone: +86-21-62489820 \\ Fax: $+86-21-62489821$
}


(C) 2012 The Author(s). Licensee IntechOpen. This is an open access article distributed under the terms of the Creative Commons Attribution 3.0 License, which permits unrestricted use, distribution, and reproduction in any medium, provided the original work is properly cited. 